\title{
Towards a deployment tool for wireless access networks with minimal power consumption
}

\author{
Margot Deruyck, Emmeric Tanghe, Wout Joseph, Willem Vereecken, Mario Pickavet, Bart Dhoedt, and Luc Martens \\ Ghent University - IBBT, Department of Information Technology (INTEC) \\ Gaston Crommenlaan 8, Bus 201, 9050 Ghent, Belgium \\ email: margot.deruyck@intec.ugent.be \\ web: www.intec.ugent.be
}

\begin{abstract}
The power consumption of wireless access networks will become an important issue in the coming years. In this paper, the power consumption of base stations for mobile WiMAX, HSPA, and LTE is modelled. This power consumption is related to the coverage of the base station. The considered technologies are compared according to their energy efficiency for different bit rates at a bandwidth of $5 \mathrm{MHz}$. For this particular case and based on the assumptions of parameters of the specifications, HSPA is the least energy-efficient technology. Until a bit rate of 11 Mbps LTE is the most energy-efficient while for higher bit rates mobile WiMAX performs the best. Furthermore the influence of MIMO is investigated. A decrease of about $80 \%$ for mobile WiMAX and about $74 \%$ for HSPA and LTE for the power consumption per covered area is found for a $4 \times 4$ MIMO system compared to a SISO system. The introduction of MIMO has thus a positive influence on the energy efficiency of the considered technologies. The power consumption and coverage model for base stations is then used to develop a prediction tool for power consumption in wireless access networks.
\end{abstract}

Index Terms - base station, coverage, MIMO, power consumption, mobile WiMAX, HSPA, LTE

\section{INTRODUCTION}

The global Information and Communication Technology (ICT) industry is an important and quickly growing contributor to $\mathrm{CO}_{2}$ emissions and energy consumption. In 2007, the total footprint of the ICT sector was 830 Megatons $\mathrm{CO}_{2} \mathrm{e}$ which is about $2 \%$ of global human emissions and equivalent to those of global aviation [1], [2]. Furthermore, the power consumption of ICT is approximately $4 \%$ of the annual energy consumption and it is expected that this number will double within the next 10 to 15 years [3].

Within ICT it is shown that the radio access networks are a large contributor to $\mathrm{CO}_{2}$ emissions [3], [4], [5]. The base stations are responsible for roughly two-thirds of the $\mathrm{CO}_{2}$ emissions of these radio access networks [4]. NTT DoCoMo recently investigated the daily power consumption per customer [5]. They found a power consumption per customer of $0.83 \mathrm{Wh}$ for a terminal and $120 \mathrm{Wh}$ for the mobile network resulting in a consumption ratio of about 1:150 for terminal versus network. The power consumption of the terminals (powered by batteries and thus already optimized) is thus negligible with respect to the power consumption of the mobile network. Therefore, it is clear that one should focus on the base stations in the wireless access networks in order to reduce the power consumption.

The purpose of this research is to model the power consumption of base stations of various wireless technologies. This power consumption is related to the coverage. Based on these characteristics, we can compare the energy efficiency of the technologies for different scenarios. Furthermore, the influence of MIMO (Multiple Input Multiple Output) is investigated and a first version of a deployment tool for minimal power is proposed.

The outline of the paper is as follows: in Section II we give a short overview of the considered technologies. In Section III the power consumption of a base station is modelled and related to the coverage. Section IV gives some results for the considered technologies obtained with the model from Section III. In Section V we give our final conclusions.

\section{TECHNOLOGIES}

The power consumption and energy efficiency of three wireless technologies is investigated: mobile WiMAX (Worldwide Interoperability for Microwave Access), HSPA (High Speed Packet Access) and LTE (Long Term Evolution).

Mobile WiMAX is a wireless technology for broadband communication based on the IEEE 802.16e interface [6] and is operating in the $2-6 \mathrm{GHz}$ band which is developed for mobile wireless applications. It uses the novel SOFDMA (Scalable Orthogonal Frequency Division Multiple Access) technique which is derived from OFDMA (Orthogonal Frequency Division Multiple Access) and supports a wide range of bandwidths to flexibly address the need for various spectrum allocation and application requirements.

HSPA is the successor of the widely deployed UMTS (Universal Mobile Telecommunications System) and works in the $2.1 \mathrm{GHz}$ band [7]. It allows networks based on UMTS to have higher data rates, and increased cell and user throughput and reduced delay. Furthermore, HSPA supports shared channel transmission. This means that the channelization codes and the transmission power in a cell are dynamically shared between users.

LTE is the newest wireless broadband technology [8]. In December 2009, world's first publicly available LTE-service was started in Scandinavia [9]. LTE is marketed as the fourth 
generation $(4 \mathrm{G})$ of radio technologies. It uses SOFDMA as multiple access technique and thus supports variable bandwidths, just like mobile WiMAX supports scalability. LTE uses the $2.6 \mathrm{GHz}$ band. In the future, LTE may also use the $800 \mathrm{MHz}$ band (digital divend frequencies).

\section{METHOD}

\section{A. Scenario}

In this investigation, the base stations are placed outdoor in a suburban environment. For the mobile stations, we considered an indoor residential scenario with a Wireless Network Interface Card (WNIC) for a laptop. Table I summarizes the configuration parameters for all technologies described in Section II.

\begin{tabular}{|l|c|c|}
\hline Parameter & Value & Unit \\
\hline Area type & Suburban & - \\
\hline Number of sectors $n_{\text {sector }}$ & 3 & - \\
\hline Height of base station & 30 & $\mathrm{~m}$ \\
\hline Height of mobile station & 1.5 & $\mathrm{~m}$ \\
\hline Coverage requirement & $90 \%$ & - \\
\hline Path loss model & Erceg C & - \\
\hline Shadowing margin & 13.2 & $\mathrm{~dB}$ \\
\hline \multicolumn{2}{|c}{ TABLE I } \\
CONFIGURATION TABLE.
\end{tabular}

We also define two technical scenarios for the outdoor base stations: a basic reference scenario and a future extended scenario. In the basic reference scenario, one receiving $(\mathrm{Rx})$ and one transmitting (Tx) antenna is considered i.e., a SISO (Single Input Single Output) system. In the extended scenario, both the base station and the receiver have multiple antennas i.e., a MIMO (Multiple Input Multiple Output) system. Here, we consider a 4x4 MIMO system.

\section{B. Power consumption of a base station}

A base station is here defined as the equipment needed to communicate with the mobile stations and with the backhaul network. A base station typically consists of several power consuming components. Fig. 1 gives an overview of these components. Some equipment is used per sector (in total $n_{\text {sector }}$ for each base station) such as digital signal processing (responsible for system processing and coding), power amplifier, transceiver (responsible for receiving and sending of signals to the mobile stations and signal generation) and the AC-DC converter. Furthermore, a base station contains equipment that is common for all the sectors such as the air conditioning and the microwave link (responsible for communication with the backhaul network in case no fiber link is available).

The power consumption of each part of the base station is a constant value (in Watt), except for the air conditioning and the power amplifier. The power consumption of the air conditioning depends on the internal and ambient temperature of the base station cabinet. We assumed an internal and ambient temperature of $25^{\circ} \mathrm{C}$. The power consumption of the power amplifier depends on the required input power $P_{T x}$

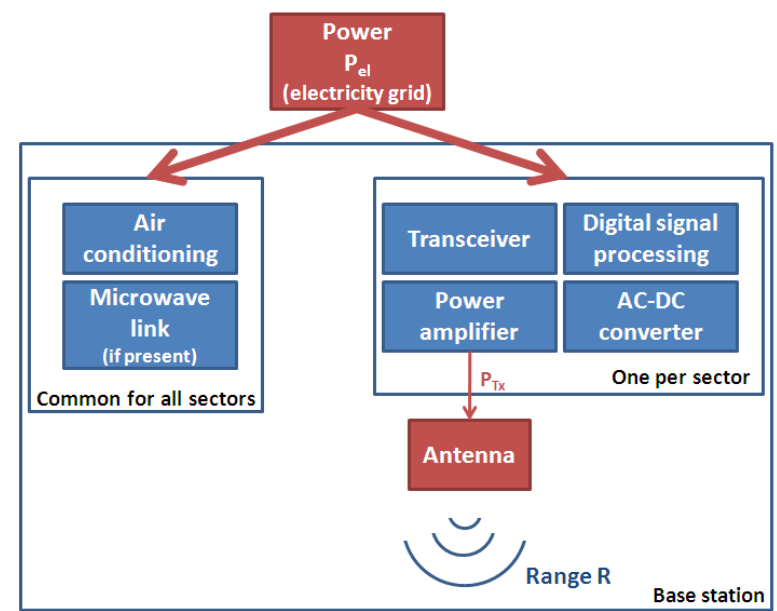

Fig. 1. Block diagram of the base station equipment

of the antenna. The power consumption $P_{e l / a m p}$ of the power amplifier (in Watt) is determined as follows [10]:

$$
P_{e l / a m p}=\frac{P_{T x}}{\eta}
$$

with $P_{T x}$ the input power of the antenna (in Watt) and $\eta$ the efficiency of the power amplifier which is the ratio of RF output power $P_{\text {out } / a m p}$ (in Watt) to the electrical input power $P_{e l / a m p}$ of the power amplifier (in Watt) [11]. The RF output power $P_{\text {out } / a m p}$ of the power amplifier corresponds with the input power $P_{T x}$ of the antenna as indicated in Fig. 1 .

Once we know the power consumption of the different components of the base station, we can calculate the power consumption $P_{e l}$ of the entire base station (in Watt):

$$
\begin{aligned}
P_{e l}= & n_{\text {sector }} \cdot\left(n_{T x} \cdot P_{\text {el } / \text { amp }}+P_{\text {el/trans }}+P_{\text {el } / \text { proc }}\right. \\
& \left.+P_{\text {el } / \text { conv }}\right)+P_{\text {el/micro }}+P_{\text {el/airco }}
\end{aligned}
$$

with $n_{\text {sector }}$ the number of sectors in the cell, $P_{\text {el/amp }}$, $P_{\text {el/trans }}, P_{\text {el/proc }}, P_{e l / c o n v}, P_{e l / m i c r o}$ and $P_{e l / a i r c o}$ are the power consumptions of the power amplifier, the transceiver, the digital signal processing, the AC-DC converter, the microwave link and the air conditioning, respectively. Furthermore, $n_{T x}$ is the number of transmitting antennas per sector. In contrast to [10], it is assumed that the signal generator is embedded in the transceiver. Table II summarises the power consumption of the different components of a base station for the considered technologies. These values are retrieved from data sheets of various manufacturers of network equipment.

\section{Calculation of range}

In this section, we want to relate the power consumption $P_{e l}$ of the base station to the wireless range $R$. To this end, we have to determine a link budget. A link budget takes all of the gains and losses of the transmitter through the medium to the receiver into account. Firstly, we need to calculate the maximum allowable path loss $P L_{\max }$ (in $\mathrm{dB}$ ) to which a transmitted signal can be subjected while still being detectable 


\begin{tabular}{|l|l|c|c|c|}
\hline Equipment & Mobile & HSPA & LTE \\
WiMAX & & \\
\hline Digital signal \\
processing & $P_{\text {el } / \text { proc }}$ & $100 \mathrm{~W}$ & $100 \mathrm{~W}$ & $100 \mathrm{~W}$ \\
\hline Power & $P_{\text {el/amp }}$ & $100 \mathrm{~W}$ & $300 \mathrm{~W}$ & $350 \mathrm{~W}$ \\
amplifier & $\eta$ & $10 \%$ & $6.67 \%$ & $6.3 \%$ \\
SISO (1x1) & $R F_{\text {out }}$ & $40 \mathrm{dBm}$ & $43 \mathrm{dBm}$ & $43 \mathrm{dBm}$ \\
\hline Power & $P_{\text {el/amp }}$ & $10.4 \mathrm{~W}$ & $10.4 \mathrm{~W}$ & $10.4 \mathrm{~W}$ \\
amplifier & $\eta$ & $11.54 \%$ & $11.54 \%$ & $11.54 \%$ \\
MIMO & $R F_{\text {out }}$ & $30 \mathrm{dBm}$ & $30 \mathrm{dBm}$ & $30 \mathrm{dBm}$ \\
\hline Transceiver & $P_{\text {el } \text { trans }}$ & $100 \mathrm{~W}$ & $100 \mathrm{~W}$ & $100 \mathrm{~W}$ \\
\hline AC-DC converter & $P_{\text {el/conv }}$ & $100 \mathrm{~W}$ & $100 \mathrm{~W}$ & $100 \mathrm{~W}$ \\
\hline Air conditioning & $P_{\text {el/airco }}$ & $690 \mathrm{~W}$ & $690 \mathrm{~W}$ & $690 \mathrm{~W}$ \\
\hline Microwave link & $P_{\text {el/micro }}$ & $80 \mathrm{~W}$ & $80 \mathrm{~W}$ & $80 \mathrm{~W}$ \\
\hline
\end{tabular}

TABLE II

POWER CONSUMPTION OF THE DIFFERENT PARTS OF THE WIRELESS BASE STATIONS.

at the receiver. The path loss is the ratio of the transmitted power to the received power of the signal [12]. It includes all of the possible elements of loss associated with interactions between the propagating wave and any objects between the transmit and receive antennas. To determine the maximum allowable path loss $P L_{\max }$ we need to take the parameters of Table III into account. Table III gives an overview of all the gains and losses that occur. It is important to remark, that $P L_{\max }$ is dependent of the input power $P_{T x}$ of the antenna and thus dependent of the output power of the power amplifier which is $\eta \cdot P_{\text {el/amp }}$.

\begin{tabular}{|c|c|c|c|}
\hline Parameter & $\begin{array}{c}\text { Mobile } \\
\text { WiMAX }\end{array}$ & HSPA & LTE \\
\hline Frequency $[\mathrm{MHz}]$ & 2500 & 2100 & 2600 \\
\hline $\begin{array}{l}\text { Maximum input power } \\
\text { of base station }[\mathrm{dBm}]\end{array}$ & 35 & 24.7 & 43 \\
\hline Antenna gain of base station [dBi] & 16 & 17.4 & 18 \\
\hline Antenna gain of mobile station [dBi] & 2 & 0 & 0 \\
\hline Number of MIMO Tx antennas & \multicolumn{3}{|c|}{1,4} \\
\hline Number of MIMO Rx antennas & \multicolumn{3}{|c|}{1,4} \\
\hline MIMO gain [dB] & \multicolumn{3}{|c|}{ 1x1: $0,4 \times 4: 12$} \\
\hline $\begin{array}{l}\text { Cyclic combining gain } \\
\text { of base station [dB] }\end{array}$ & \multicolumn{3}{|c|}{3} \\
\hline Soft handover gain $[\mathrm{dB}]$ & 0 & 1.5 & 0 \\
\hline Feeder loss of base station $[\mathrm{dB}]$ & 0.5 & 0 & 2 \\
\hline Feeder loss of mobile station $[\mathrm{dB}]$ & \multicolumn{3}{|c|}{0} \\
\hline Fade margin $[\mathrm{dB}]$ & \multicolumn{3}{|c|}{10} \\
\hline Cell interference margin $[\mathrm{dB}]$ & \multirow{2}{*}{\multicolumn{3}{|c|}{$\frac{2}{0}$}} \\
\hline User speed $[\mathrm{km} / \mathrm{h}]$ & & & \\
\hline Bandwidth [MHz] & 5 & 5 & 5 \\
\hline Receiver SNR [dB] & $\begin{array}{l}{[6,8.5,11.5} \\
15,19,21]^{1}\end{array}$ & $\begin{array}{c}-3.1,0.1,3.4 \\
6,7.1,9.6 \\
15.6]^{2} \\
\end{array}$ & $\begin{array}{c}-1.5,3,10.5 \\
14,19,23 \\
23,29.4]^{3} \\
\end{array}$ \\
\hline Number of used subcarriers & 360 & 1 & 301 \\
\hline Number of total subcarriers & 512 & 1 & 512 \\
\hline Noise figure of mobile station $[\mathrm{dB}]$ & 7 & 9 & 8 \\
\hline $\begin{array}{l}\text { Implementation loss } \\
\text { of mobile station }[\mathrm{dB}]\end{array}$ & 2 & 0 & 0 \\
\hline Duplexing & \multicolumn{3}{|c|}{ TDD } \\
\hline Building penetration loss [dB] [13] & \multicolumn{3}{|c|}{8.1} \\
\hline
\end{tabular}

(1) [1/2 QPSK, 3/4 QPSK, 1/2 16-QAM, 3/4 16-QAM, 2/3 64-QAM, 3/4 64-QM]

(2) [1/4 QPSK, 1/2 QPSK, 3/4 QPSK, 3/4 8-QAM, 1/2 16-QAM, 3/4 16-QAM, 3/4 64-QAM]

(3) [1/3 QPSK, 1/2 QPSK, 2/3 QPSK, 1/2 16-QAM, 2/3 16-QAM, 4/5 16-QAM, 1/2 64-QAM, 2/3 64-QAM]

TABLE III

LINK BUDGET TABLE FOR THE WIRELESS TECHNOLOGIES

Once we know the maximum allowable path loss $P L_{\max }$, we can determine the maximum range $R$ (in metres) we can reach with the base station of a certain technology [10]:

$$
R=g^{-1}\left(P L_{\max }-S M \mid f, h_{B S}, h_{M S}\right)
$$

with $P L_{\max }$ the maximum allowable path loss (in $\mathrm{dB}$ ), $S M$ the shadowing margin (in $\mathrm{dB}$ ), $f$ the frequency (in $\mathrm{Hz}$ ), $h_{B S}$ the height of the base station (in metres) and $h_{M S}$ the height of the mobile station (in metres). The shadowing margin depends on the standard deviation of the path loss model, the coverage percentage and the outdoor standard deviation. Here, we consider a coverage percentage of $90 \%$. The values for the other parameters can be found in Table I. The function $g($. depends on the used path loss model e.g., the HATA model and the Erceg model [14], [15]. In this paper, we use the Erceg C model. The quantity before the "|" in (3) is a variable and varies over a continuous interval, while the quantities after the "|" in (3) are parameters which take only one discrete known value.

\section{Tool for prediction of power consumption in wireless access networks}

The model described in Section III is used in a deployment tool for green wireless access networks. The purpose of the tool is to cover a specified area, the target area, with a wireless technology and with a minimal power consumption. Our tool can optimise the current network of an operator or can support the deployment of a new network. In the current version only existing base station sites (macrocells) are used. Each base station site has three antennas but in the current version there is no radiation pattern implemented i.e., it is assumed that the antenna sends the same amount of power in each direction. Therefore, the coverage area of the base station is visualized by a circle.

For the calculation of the optimal solution, a genetic search algorithm is used. In order to determine if a solution is better than another, two different fitness functions are combined to one global fitness function. The first fitness function is the coverage fitness $f_{\text {cov }}$ and is defined as:

$$
f_{\text {cov }}=100 \cdot \frac{A_{\text {target }} \cap A_{\text {sol }}}{A_{\text {target }}}
$$

with $A_{\text {target }}$ the area of the target area to be covered (in $\mathrm{km}^{2}$ ) and $A_{\text {sol }}$ the area covered by the current solution. $f_{c o v}$ is expressed as a percentage and indicates how good the target area is covered by the current solution and $\cap$ represents the cross-section of the two areas. The higher $f_{\text {cov }}$, the better the area covered by the current solution corresponds with the target area.

The second fitness function is the power consumption fitness $f_{\text {pow }}$ and is defined as:

$$
f_{\text {pow }}=100-\left(\frac{P_{\text {sol }}}{P_{\text {max }}} \cdot 100\right)
$$

with $P_{\text {sol }}$ the power consumption of the current solution and $P_{\max }$ the power consumption of the most energy-inefficient deployment i.e., the deployment with the highest power consumption, for the target area. In order to determine $P_{\max }$, 
the highest power consumption of each base station site is determined based on equation (2) from Section III. Furthermore, each base station site is activated when the highest power is consumed. In this way, the power consumption of the most energy-inefficient deployment is determined and used as reference to decide whether a solution is better than the other or not. The higher $f_{\text {pow }}$, the better the solution is i.e., a higher value for $f_{\text {pow }}$ corresponds with a lower power consumption. Equations (4) and (5) are then combined in one global fitness function $f_{\text {tot }}$ defined as:

$$
f_{\text {tot }}=f_{\text {cov }}+g\left(f_{\text {cov }}\right) \cdot f_{\text {pow }}
$$

with

$$
g\left(f_{\text {cov }}\right)=\left\{\begin{array}{lr}
0, & f_{\text {cov }}<90 \\
5 * \frac{f_{\text {cov }}-90}{5}, & 90 \leq f_{\text {cov }}<95 \\
5, & \text { else }
\end{array}\right.
$$

The higher $f_{\text {tot }}$, the better the solution is. The maximum value for $f_{\text {tot }}$ when equation (6) is used, is 600 i.e., when both $f_{\text {cov }}$ and $f_{\text {pow }}$ equal 100 . We chose for this kind of global fitness function because of the trade-off between coverage and power consumption. As soon as a coverage of $90 \%$ is reached, the power consumption is taken into account. One can see that in this way a good coverage is easily obtained. The power consumption can than be minimized without losing much coverage. Important to remark is that the boundaries of 90 and 95 for $f_{\text {cov }}$ in equation (6) can be chosen freely.

A genetic search algorithm is also characterized by its mutations. The purpose of these mutations is to generate new solutions which are hopefully better than the current solution. For our deployment tool, four different mutations are defined:

- Make an inactive base station active.

- Make an active base station inactive.

- Add $1 \mathrm{dBm}$ to the input power of the antenna of an active base station.

- Remove $1 \mathrm{dBm}$ of the input power of the antenna of an active base station.

Which and how a base station site is adapted, is determined at random. The algorithm is stopped when a maximum number of generations or the maximum running time is exceeded. The longer the tool runs, the better the solution will be. One will have to make a trade-off between the execution time of the simulation and the quality of the solution.

\section{RESUlts}

\section{A. Comparison of technologies}

In this section, the considered wireless technologies are compared for a bandwidth of $5 \mathrm{MHz}$. The parameters given in Tables I, II and III are used.

Fig. 2 shows the power consumption $P C_{\text {area }}$ per covered area (in $\mathrm{W} / \mathrm{m}^{2}$ ) as a function of the bit rate (in Mbps). The power consumption $P C_{\text {area }}$ per covered area (in $\mathrm{W} / \mathrm{m}^{2}$ ) is defined as [10]:

$$
P C_{\text {area }}=\frac{P_{e l}}{\pi \cdot R^{2}}
$$

with $P_{e l}$ the power needed from the electricity grid (in Watt) and $R$ the range (in metres). This parameter allows us to determine which technology is the most energy-efficient. This is the technology with the lowest value for $P C_{\text {area }}$.

In general, Fig. 2 shows that $P C_{\text {area }}$ increases for increasing bit rates for each technology and thus becomes less energy-efficient when a higher bit rate is obtained. This can be explained by the fact that higher bit rates correspond with higher receiver SNRs as shown in Table III. Higher receiver SNRs correspond with smaller ranges. Based on equation ( 7), one can see that a higher $P C_{\text {area }}$ corresponds with a smaller range for the same $P_{e l}$.

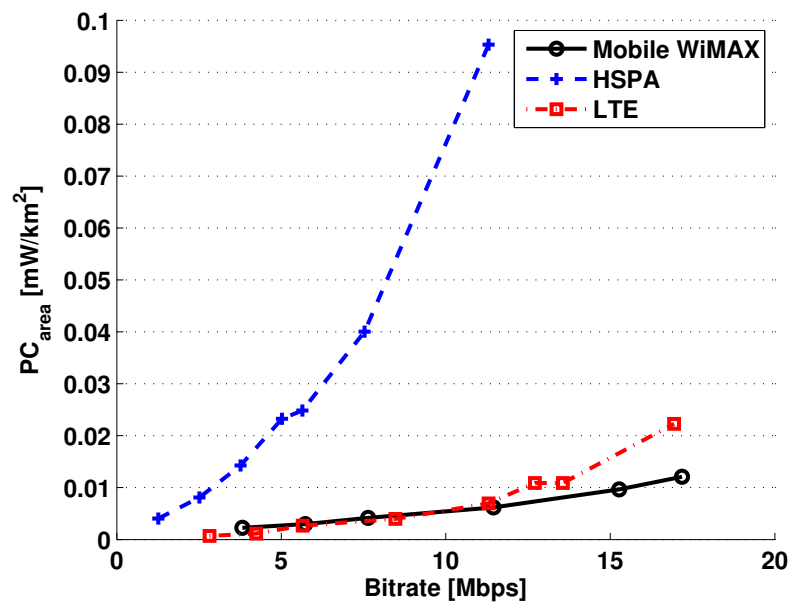

Fig. 2. Comparison of the technologies for a bandwidth of $5 \mathrm{MHz}$

Fig. 2 shows that HSPA is the least energy-efficient technology for the considered case because of its high power consumption and rather low range. The high power consumption is caused by the low efficiency of the power amplifier (Table II) and the low range by the low input power of the antenna (Table III). Furthermore, one can see that unto a bit rate of approximately $11 \mathrm{Mbps}$, LTE is the most energy-efficient, while for higher bit rates mobile WiMAX is the most energyefficient one. Until a bit rate of $11 \mathrm{Mbps}$, a high range is obtained for LTE resulting in a low $P C_{\text {area }}$ because of the low receiver SNR (Signal-to-Noise Ratio) as shown in Table III. However, for bit rates higher than 11 Mbps mobile WiMAX has lower receiver SNRs than LTE leading to higher ranges for mobile WiMAX. Mobile WiMAX has also a lower power consumption than LTE because of the high efficiency of its power amplifier (Table II) resulting in a lower $P C_{\text {area }}$. For a bit rate of approximately 5.7 Mbps for mobile WiMAX $P C_{\text {area }}=3.0 \mathrm{~mW} / \mathrm{m}^{2}$ and $P C_{\text {area }}=2.7 \mathrm{~mW} / \mathrm{m}^{2}$ for LTE while for a bit rate of approximately $17 \mathrm{Mbps} P C_{\text {area }}=$ $12.1 \mathrm{~mW} / \mathrm{m}^{2}$ for mobile WiMAX and $P C_{\text {area }}=22.3 \mathrm{~mW} / \mathrm{m}^{2}$ for LTE.

\section{B. Influence of MIMO}

In this section, multiple receiving $(\mathrm{Rx})$ and transmitting (Tx) antennas i.e., MIMO (Multiple Input Multiple Output), 
are introduced. A 4x4 MIMO (4 Tx and $4 \mathrm{Rx}$ ) is assumed. We compare the considered technologies for a bandwidth of $5 \mathrm{MHz}$ and a bit rate of approximately $5 \mathrm{Mbps}$ for the SISO ( $1 \mathrm{Rx}$ and $1 \mathrm{Tx}$ ) system and a bit rate of approximately $20 \mathrm{Mbps}$ for the $4 \times 4$ MIMO system. Table IV lists the results for $P_{e l}, R$ and $P C_{a r e a}$ for the SISO and the $4 \times 4$ MIMO system.

\begin{tabular}{|c|c|c|c|}
\hline 1x1 SISO & $\begin{array}{c}\text { Mobile } \\
\text { WiMAX }\end{array}$ & $\overline{\text { HSPA }}$ & LTE \\
\hline$\overline{P_{e l}[\mathrm{~W}]}$ & 1764.9 & 2567.4 & 2620.1 \\
\hline$R[\mathrm{~m}]$ & 434.0 & 187.5 & 557.0 \\
\hline$P C_{\text {area }}\left[\mathrm{mW} / \mathrm{m}^{2}\right]$ & 3.0 & 23.2 & 2.7 \\
\hline 4x4 MIMO & $\begin{array}{c}\text { Mobile } \\
\text { WiMAX }\end{array}$ & HSPA & LTE \\
\hline$P_{e l}[\mathrm{~W}]$ & 1998.8 & 3744.8 & 3744.8 \\
\hline$R[\mathrm{~m}]$ & 1006.6 & 434.9 & 1292.0 \\
\hline$P C_{\text {area }}\left[\mathrm{mW} / \mathrm{m}^{2}\right]$ & 0.6 & 6.3 & 0.7 \\
\hline
\end{tabular}

TABLE IV

COMPARISON OF THE WIRELESS TECHNOLOGIES FOR SISO AND 4X4 MIMO

If we compare the SISO system to the $4 \mathrm{x} 4$ MIMO system, an increase of about $13 \%$ is found for the power consumption of mobile WiMAX and about $46 \%$ and $43 \%$ respectively for HSPA and LTE, while the range increases with $132 \%$ for each technology. This results in a decrease of about $80 \%$ for $P C_{\text {area }}$ (and thus an increase in energy efficiency) of mobile WiMAX and about $74 \%$ for HSPA and LTE when using a $4 \mathrm{x} 4$ MIMO system. In general, we conclude that the energy efficiency increases when multiple antennas are used.

\section{Results with tool for prediction of power consumption in wireless access networks}

In this section, we investigate how much electrical power we need to cover a pre-defined area with base stations of each technology. Only one technology is used at a time. A network for a new operator is rolled out. However, there is only limitation: the new operator has to re-use the existing base stations of the other operators. This means that the location of the existing base stations sites and the heights of the antennas at these sites are kept but the other settings (frequency, antenna gain and the input power) are set to default settings which corresponds with the settings shown in Table III. The location of the existing base station sites, along with a number of settings of the base stations sites are retrieved from a shapefile given by BIPT (Belgisch Instituut voor Postdiensten en Telecommunication) [16]. A total number of 8095 antennas spread over 840 base station sites and exploited by 4 operators can be found in the shapefile. In the used shapefile three sorts of sites can be found: GPRS (General Packet Radio Service) sites (5262 antennas at 764 sites), UMTS sites (2446 antennas at 538 sites) and WiMAX sites (387 antennas at 86 sites). Some sites support more than one technology.

Fig. 3(a) shows the suburban area we want to cover. This area is Brussels $\left(149 \mathrm{~km}^{2}\right)$, capital region of Belgium. Fig. 3(b) shows the existing base station sites in this area.

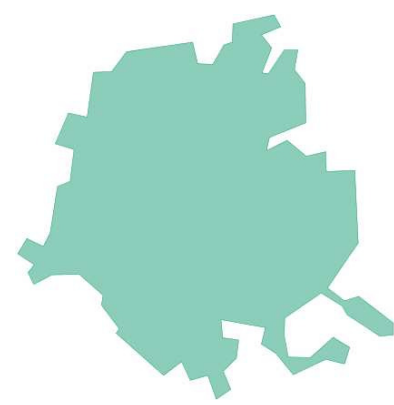

(a)

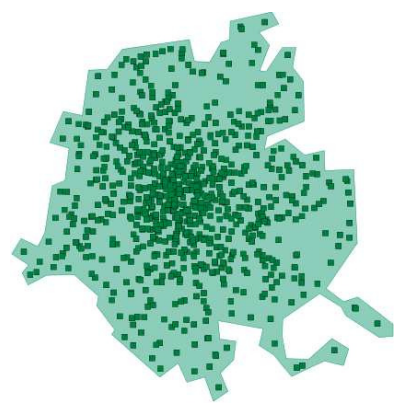

(b)
Fig. 3. The area to be covered (a) and the sites available in this area (b)

We will cover Brussels with the three considered technologies for both a SISO and a 4x4 MIMO system. In order to make a fair comparison we assume a bit rate of $1 \mathrm{Mbps}$ for the SISO system and a bit rate of $4 \mathrm{Mbps}$ for the $4 \mathrm{x} 4 \mathrm{MIMO}$ system. For mobile WiMAX, a total of 128 subcarriers and the 3/4 QPSK modulation is used. For HSPA, the 1/4 QPSK modulation and for LTE a total of 128 subcarriers is used and the $1 / 2$ QPSK modulation. The algorithm stops running when a maximum number of generations of 5000 is reached or when the simulation duration exceeds $14400 \mathrm{~s}$. A longer simulation duration and/or a higher number of maximum generations could result in a more optimized solution. However, one has to make a trade-off between the quality of the solution and the duration of the simulation.

Fig. 4 shows as an illustration the energy-efficient deployment (resulting from the tool) in Brussels for mobile WiMAX for both the SISO system (Fig. 4(a)) and the MIMO system (Fig. 4(b)). Table $\mathrm{V}$ gives an overview of the results for the considered technologies.

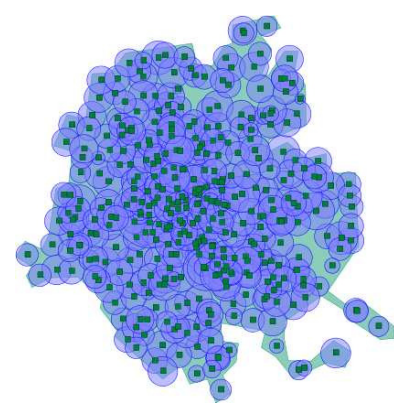

(a)

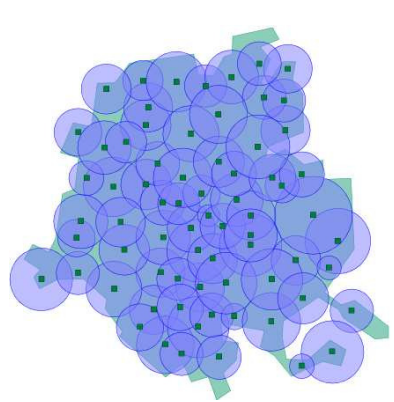

(b)
Fig. 4. Deployment of mobile WiMAX for a SISO (a) and a 4x4 MIMO system (b)

Table V shows that for the considered case LTE is the best solution for both the SISO (power consumption $48.4 \mathrm{~kW}$ ) and the MIMO system (power consumption $15.9 \mathrm{~kW}$ ). LTE has the lowest total power consumption, the highest global fitness and needs the lowest number of base stations. HSPA performs the worst for this case which corresponds with the results from Section IV. The coverage of Brussels with a 


\begin{tabular}{|c|c|c|c|}
\hline 1x1 SISO & $\begin{array}{c}\text { Mobile } \\
\text { WiMAX }\end{array}$ & HSPA & $\overline{\text { LTE }}$ \\
\hline Total power consumption $[\mathrm{kW}]$ & 123.2 & 377.6 & 48.4 \\
\hline$f_{\text {cov }}$ & $95.0 \%$ & $85.2 \%$ & $97.2 \%$ \\
\hline$f_{\text {pow }}$ & $55.6 \%$ & $18.6 \%$ & $90.2 \%$ \\
\hline$f_{\text {tot }}$ & 372.8 & 85.2 & 547.9 \\
\hline Number of used sites & 374 & 711 & 85 \\
\hline 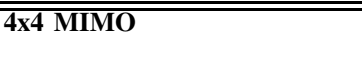 & $\begin{array}{c}\text { Mobile } \\
\text { WiMAX }\end{array}$ & $\overline{\overline{\text { HSPA }}}$ & $\overline{\overline{\text { LTE }}}$ \\
\hline Total power consumption [kW] & 28.2 & 118.6 & 15.9 \\
\hline$f_{\text {cov }}$ & $96.4 \%$ & $96.2 \%$ & $99.9 \%$ \\
\hline$f_{\text {pow }}$ & $91.6 \%$ & $84.6 \%$ & $98.0 \%$ \\
\hline$f_{\text {tot }}$ & 554.5 & 519.4 & 590.1 \\
\hline Number of used sites & 71 & 137 & 17 \\
\hline
\end{tabular}

TABLE V

COMPARISON OF THE WIRELESS TECHNOLOGIES FOR THE COVERAGE OF BRUSSELS

HSPA SISO system is about $10 \%$ lower than for the other two technologies. For the SISO system, the coverage with HSPA is below the $90 \%$, so there was no attempt to reduce the power consumption resulting in a very low global fitness. However, with the MIMO system a good coverage $(96.2 \%)$ is found for HSPA. Furthermore, Table V shows that for each technology the results for a $4 \times 4$ MIMO system are better than for a SISO system: the total power consumption is lower, the global fitness is higher and the number of used sites is lower than for the SISO system. This confirms the results from Section IV. The proposed tool of Section III-D can be used for network planning with optimal energy efficiency.

\section{CONCLUSION}

In this paper, the power consumption for three different wireless technologies, namely mobile WiMAX, HSPA, and LTE, is investigated based on parameter assumptions for the three technologies. This power consumption is related to the coverage of their base stations. The base stations are placed outdoor and for the mobile stations an indoor residential scenario with a Wireless Network Interface Card (WNIC) for each technology was considered. The energy efficiency per covered area $P C_{\text {area }}$ was compared for different bit rates and for the considered technologies (bandwidth of $5 \mathrm{MHz}$ ). LTE is the most energy efficient until a bit rate of approximately 11 Mbps. For higher bit rates, the best solution is mobile WiMAX. The lowest efficiencies were obtained for HSPA for the considered scenario. Furthermore, the influence of MIMO on the energy efficiency was investigated. HSPA is again the least energy-efficient technology. LTE performs the best until a bit rate of approximately $22 \mathrm{Mbps}$ and for higher bit rates mobile WiMAX is the most energy-efficient. However, the introduction of MIMO has a positive influence on the energy efficiency of each technology. For mobile WiMAX $P C_{\text {area }}$ decreases with about $80 \%$ if we compare the SISO system with the $4 \times 4$ MIMO system. For HSPA and LTE this decrease is about $74 \%$.

The theoretical power consumption and coverage model for the base stations is finally used in a prediction tool and applied on the Brussels capital region. The proposed tool can be used for network planning with optimal energy efficiency.

\section{ACKNOWLEDGMENT}

The work described in this paper was carried out with support of the IBBT-project GreenICT and the BONE project ("Building the Future Optical Network in Europe"), a Network of Excellence funded by the European Community's Seventh Framework.

W. Joseph is a Post-Doctoral Fellow of the FWO-V (Research Foundation Flanders).

\section{REFERENCES}

[1] "SMART 2020: Enabling the low carbon economy in the information age," The Climate Group on behalf of the Global eSustainability Initiative (GeSI), Tech. Rep., 2008. [Online]. Available: http://www.smart2020.org/_assets/files/02_Smart2020Report.pdf

[2] "Gartner Estimates ICT Industry Accounts for 2 Percent of Global CO2 Emissions," Gartner, Tech. Rep., 2007. [Online]. Available: http://www.gartner.com/it/page.jsp?id=503867

[3] M. Pickavet, W. Vereecken, S. Demeyer, P. Audenaert, B. Vermeulen, C. Develder, D. Colle, B. Dhoedt, and P. Demeester, "Worldwide Energy Needs for ICT: the Rise of Power-Aware Networking," in 2008 IEEE ANTS Conference, Bombay, India, December 2008, pp. 1-3.

[4] Ericsson, "Sustainable energy use in mobile communications," White paper, August 2007.

[5] M. Etoh, T. Ohya, and Y. Nakayama, "Energy Consumption Issues on Mobile Network Systems," in International Symposium Issues on Mobile Network Systems, 2008.

[6] Part 16: Air Interface for Fixed and Mobile Broadband Wireless Access Systems: Amendment 2: Physical and Medium Access Control Layers for Combined Fixed and Mobile Operation in Licensed bands and Corrigendum 1, IEEE Computer Society and the IEEE Microwave Theory and Techniques Society, February 2006. [Online]. Available: www.ieee802.org/16

[7] 3rd Generation Partnership Project: Technical Specification Group Radio Access Network: Physical layer aspects of UTRA High Speed Downlink Packet Access (Release 4), TR 25.848 v4.0.0., 3GPP, March 2001.

[8] LTE: 3rd Generation Partnership Project: Technical Specification Group Radio Access Network: Evolved Universal Terrestrial Radio Access (EUTRA): User Equipment (UE) radio transmission and reception (TS 36.101 v9.1.0 Release 9) , 3GPP, September 2009.

[9] TeliaSonera, "TeliaSonera first in the world with 4G services," December 2009. [Online]. Available: http://www.teliasonera.com/News-and-Archive/Pressreleases/2009/TeliaSonera-first-in-the-world-with-4G-services/

[10] M. Deruyck, W. Vereecken, E. Tanghe, W. Joseph, M. Pickavet, L. Martens, and P. Demeester, "Power consumption in Wireless Access Networks," in 2010 European Wireless Conference, 2010.

[11] F. H. Raab, P. Asbeck, S. Cripps, P. B. Kenington, Z. B. Popovic, N. Pothecary, J. F. Sevic, and N. O. Sokal, "RF and Microwave Power Amplifier and Transmitter Technologies - Part 1," High Frequency Electronics, pp. 22-36, May 2003.

[12] S. Saunders, Antennas and Propagation for Wireless Communication Systems. Wiley, 1999.

[13] D. Plets, W. Joseph, L. Verloock, L. Martens, H. Gauderis, and E. Deventer, "Extensive Penetration Loss Measurements and Models for Different Building Types for DVB-H in the UHF Band," IEEE Transactions on broadcasting, vol. 55, no. 2, pp. 213 - 222, June 2009.

[14] M. Hata, "Empirical Formula for Propagation Loss in Land Mobile Radio Services," IEEE Transactions on Vehicular Technology, vol. 29, no. 3, pp. 317-325, August 1980.

[15] V. Erceg, L. Greenstein, S. Tjandra, S. Parkoff, A. Gupta, B. Kulic, A. Julius, and R. Bianchi, "An Empirically Based Path Loss Model for Wireless Channels in Suburban Environments," IEEE Journal on Selected Areas in Communications, vol. 29, no. 7, pp. 1205-1211, July 1999.

[16] Belgisch Instituut voor Postdiensten en Telecommunicatie (BIPT), "www.sites.bipt.be." 